\title{
LA IDEA HEGELIANA DE “LIBERTAD” COMO FACTOR CORRECTIVO DEL LIBERALISMO
}

\section{Fernando Aranda Fraga}

Universidad Adventista del Plata

\section{Introducción}

Un siglo y medio largo ha transcurrido ya desde que G.W.F. Hegel produjera una de las obras políticas más polémicas y debatidas durante el presente siglo. Nos referimos a la Filosofia del Derecho, obra singular de este filósofo alemán a quien le ha sido deparado por el destino el honor reservado a unos pocos de perdurar en el tiempo, no sólo como uno de los principales forjadores del pensamiento político, sino también como uno de los máximos representantes del pensamiento en su totalidad. debido a la multiplicidad temática y profundidad de su obra filosófica.

Transcurrido este lapso temporal desde su época hasta la nuestra, nos preguntamos aún hoy hasta qué punto su pensamiento sigue vivo en un mundo como el actual tan distinto del que lo vio nacer y crecer, y al que, en cierto modo, también dejó registrado bajo la mirada realista que le imprimiera a la letra de su pluma. Habida cuenta de que Hegel tuvo la capacidad de percibir su tiempo y plasmarlo en el pensamiento, ¿podemos, además, encontrar en él elementos que nos conduzcan al logro 
de una mayor comprensión de los problemas sociales y políticos del mundo de hoy? ¿Hasta qué punto tiene vigencia, todavía, su postura en relación con la sociedad y el Estado? y ¿en qué sentido podemos seguir utilizando sus categorías de análisis sin pasar por anacrónicos?

Si quisiéramos encerrar en una frase, lo más reducida posible, la esencia de la problemática socio-política del mundo en que vivimos, donde quiera que habitemos, quizás diríamos que nuestra vida ha llegado a un grado tal de individualismo que escasamente caemos en la cuenta de lo que les sucede, y apenas de que realmente existen, nuestros más próximos acompañantes $\mathrm{y}$ allegados, con quienes compartimos la mayor parte de las horas del día. Paulatinamente, esta vivencia se fue haciendo carne en nuestras vidas y ya casi ni siquiera reparamos en ello. Paradójicamente, este alto grado de privatización de la existencia no trajo a la humanidad un mayor desarrollo de las libertades individuales, ni mucho menos, para no hablar del grado de bienestar logrado por quienes han podido participar de los beneficios que esta situación pudo darles. Tendremos en cuenta, por otra parte, que lo dicho anteriormente pone al descubierto, en el sector de la población más desfavorecida, una pérdida casi total de las libertades, como consecuencia de una desigualdad cuasicongénita e irradicable que lo ha sumido en un tipo de existencia infra-humana, por debajo de los niveles mínimos de una vida dignamente aceptable.

Es en este contexto, ante el hoy más que evidente hecho de la unificación ideológica del mundo -lo cual significa algo totalmente distinto a la tan mentada "muerte de las ideologías"-, que se nos ocurre que la pretendida búsqueda hegeliana de un concepto racional de libertad podría servir para iluminar en parte esta problemática del mundo actual. En esto consiste la hipótesis central de nuestro trabajo, idea que pivotea en tres frentes, 
buscando su racionalidad en el pensamiento que la funda, el de Hegel, en la comprensión que éste tiene de la historia y por último, por comparación, en el análisis de ciertos acontecimientos históricos que lo precedieron y que lo sobrevivieron. Como base de nuestra hipótesis de trabajo partimos de la intención hegeliana de querer fijar las condiciones de realización de la idea de libertad en el mundo. Para ello será necesaria la exigencia de una sustancial racionalidad en todo ámbito en que se den relaciones humanas: la familia, la sociedad. el Estado. En definitiva, la exigencia de un "derecho racional".

Sabido es el hecho de que Hegel valoró la libertad de la polis griega, como así también su reconocimiento de otros hitos que determinaron la realización de la idea de libertad en la historia, a saber: el surgimiento de los derechos de la persona en Roma, el descubrimiento de la conciencia a partir del cristianismo, la hegemonia del sujeto en la modernidad, etc., todo lo cual condujo a nuestro pensador a intentar dejar en claro las distintas funciones y poner cada cosa en su lugar. Así dió origen a la división y complementación de esferas: la sociedad civil y el Estado. En cada una de ellas habrían de cumplirse los requerimientos de la vida del hombre moderno. En base a este esquema estructuramos el presente trabajo, culminando con el leitmotiv del mismo y que refiere inmediatamente a la supuesta actualidad del pensamiento hegeliano, en un intento de responder a las preguntas antes formuladas.

\section{La libertad en la sociedad clásica: Del mundo griego al mundo cristiano}

Vista desde una perspectiva actual (moderna), la sociedad clásica nos resulta opresora de los derechos individuales y protectora de los derechos políticos, perspectiva que padece un inevitable anacronismo, producto de sustanciales 
cambios ocurridos en el puesto del propio hombre dentro del cosmos. El papel que cumplía el hombre griego en su mundo era muy distinto del que actualmente cumple. De aquí derivarán los diferentes ámbitos de libertad y las mencionadas dificultades de interpretación.

El análisis contextual del mundo griego nos muestra una sustancial politización y sacralización de la existencia, que permaneció constante en el horizonte del mundo cultural griego hasta el momento de la helenización. Las filosofías de Platón y de Aristóteles fueron sus figuras paradigmáticas. La transformación del mundo griego en romano trajo consigo una redefinición del concepto de libertad, incipiente aún, sin algunos elementos particularizados que poco más tarde sobrevendrán como producto del advenimiento del cristianismo al mundo.

La polis griega encarnaba belleza, felicidad, bien, libertad. El arte fue para el hombre el mejor vehículo para expresar tales sentimientos; la religión era el estilo de vida por el cual se fueron edificando tales valores. En la polis, religión y política, se identificaban; Atenea era el verdadero dios de Atenas. El hombre hallaba la sustancia de lo divino en su mundo, en su patria, lo cual le permitía vivir en unión con una totalidad de características divino-humano-políticas. Esta religión inmanente le permitía al hombre griego sentirse a sí mismo en una unidad con sus conciudadanos. La unión de lo sacro con lo profano y de lo místico con lo político les permitía vivir su propia vida concreta, altamente politizada, como su única y verdadera meta, como la máxima aspiración de su realización ética.

El ciudadano griego, en su república, que no era otra cosa que la polis, era libre, feliz; gozaba de su libertad y ésta era ejercida por él positivamente. En Grecia tenemos, pues, que el 
ciudadano gozaba de una libertad plena que comprendía la totalidad de sus experiencias, todo ello en el ámbito de la polis. El significado prístino del término "sociedad" no es otra cosa que "unión", "asociación", "koinonia" es el término que se usa en griego. En la filosofía política aristotélica no aparece separado lo que para el hombre de los epígonos de la modernidad, y más aún para nosotros, hoy, son dos cosas distintas y separadas: el Estado y la sociedad. De acuerdo con Aristóteles ambas conformaban una unidad, una "totalidad social" (koinonia politiké), donde lo civil se hallaba entremezclado y hasta encubierto por lo político. El estado aristotélico era idéntico a la sociedad civil. El Estado no contiene en sí a la sociedad, es sociedad, o, más precisamente, es una sociedad política.

La identificación de lo público con lo privado resulta un concepto meridiano para la comprensión del significado de la libertad en Grecia y la antigüedad inmediata posterior. Cabe señalar que las mencionadas implicancias de la filosofía social y política griega, eran consecuencias derivadas de presupuestos metafísicos que subyacían como su más sólido fundamento cultural.

Esta libertad de la polis griega, positiva, efectiva y concreta conlleva, a la luz de la metafísica de la modernidad y sus consecuencias político-sociales, su obligada crítica, la cual se constituye en explicación de su paulatina transformación. Una transformación que se logrará a partir del establecimiento de ciertos hitos, de los cuales habremos de ocuparnos más adelante. Esta libertad positiva adolecía de ciertos problemas, tales como su selectividad, puesto que sólo podían gozar de ella los ciudadanos reconocidos y, además, era una libertad irreflexiva, incapaz de una autocrítica que la catapultara hacia el desenvolvi- 
miento de su transformación creativa (1).

Tampoco resultó muy feliz, comparándola con los riesgos de la libertad positiva, el advenimiento al mundo de la "libertad negativa". El aumento del poderío económico de los imperios, tanto en Atenas como en Roma, contribuyó a la formación de una aristocracia a la cual le cedieron libremente el poder, que aquélla, desconociendo la fuente de donde éste había emanado, llegó a consolidar por medio de una extraña mezcla de violencia, por su parte, y profunda despreocupación por la totalidad por parte del ciudadano (2). El Estado dejó ya de ser incumbencia del hombre común, pasando, así, a ser dominio de uno solo o de unos pocos. Cada individuo pasó a ocupar su parcela. La utilidad llegó a ser el valor imperante, ya sea en cuanto a lo requerido por el Estado a sus ciudadanos como a la motivación que animaba la vida de éstos. Toda actividad era ejercida en función de lo individual, y ya no más en función de totalidad alguna.

Resumiendo, la filosofía social de los griegos era un producto derivado de los presupuestos metafísicos que condicionaron su mundo. El hombre estaba tan consustanciado con su entorno que todo lo que hacía y pretendía en esta vida era hecho en aras de la unión con los demás miembros de una totalidad de la que formaba parte. Mundo político y mundo social y económico se superponían en una sustancial y mancomunada convivencia. El ciudadano de la ciudad-Estado participaba de la vida de su ciudad, era él quien le otorgaba sentido. La polis era el primero y último objetivo de su existencia: a ella le debía su

(1) De Zan, J., Libertad. poder y discurso. Bs.As.. Editorial Almagesto. 1993, p. 51.

(2) Hegel, Escritos de juventud, Madrid, Fondo de Cultura Económica, 1978, pp. 151 y 152. 
el primero y último objetivo de su existencia: a ella le debía su asentimiento y obediencia, lo cual ejercía de manera no forzada, sino, por el contrario, al modo de un feliz idilio en el que tenía parte activa. Los defectos de la polis griega fueron su elitismo dominante y la ausencia de una conciencia crítica que fuera capaz de tomar distancia de sí misma. Finalmente, esto último la habría de llevar a su auto-atrofia y postrera extinción.

Con el tiempo y su consiguiente transformación, la sociedad-Estado se fue re-definiendo a la par que la vida humana iba trocando sus metas y propósitos esenciales.

\section{Sociedad y libertad: precisiones terminológicas y semánticas}

Con el advenimiento del cristianismo al mundo un nuevo concepto de libertad se instala en el ser del hombre, fundado en el valor que ahora adquiere la persona. La pérdida de libertad positiva encontró su compensación en la adquisición de otro tipo de libertad: la libertad formal o negativa, ya ejercida en las postrimerías del Helenismo y con vigencia plena entre la ciudadanía romana. Esta libertad negativa tuvo una radical importancia para el fortalecimiento del desarrollo de la libertad concreta e hizo posible el surgimiento de una conciencia crítica ante la tradición, a partir de una toma de distancia de cualquier autojustificación del ser.

El sentido antiguo de sociedad permaneció muy similar a través de toda la edad media hasta entrada la modernidad, de manera que el Estado medieval continuó siendo idéntico a la sociedad. No había aún dos nombres para dos realidades distin- 
tas o disímiles (3). La fórmula clásica: civitas sive societas civilis sive res publica, perduró en el tiempo como la clave de comprensión de toda la filosofía política vetero-europea, tematizada en el medioevo por San Alberto Magno y Santo Tomás de Aquino, retomada en la modernidad por Bodin, Melanchton, Hobbes, Spinoza, Locke, y finalmente Kant (4). Explícitamente señalan, tanto San Alberto Magno como Bodin, que "el Estado es la sociedad civil o política" (5).

Ahora bien, una vez que hemos señalado el hecho de la identificación, nos importa aquí destacar el tipo de relación que guarda la sociedad en cada época con la idea de libertad que pervive en ella. Tal identificación venía encubriendo desde la antigüedad y en secuencia sucesiva dos aspectos de la libertad concreta; ya lo hemos esbozado al explicar el pasaje histórico y la transformación de la libertad positiva en libertad negativa, sin que este devenir haya quedado fijado en forma definitiva hasta entrada la modernidad.

Volviendo a la significación que la modernidad dio al concepto de "sociedad civil", "Melanchton y Spinoza divergen formalmente de la definición de 'civitas' solamente en que la equiparan con la 'societas civium'..." (6). Tal equiparación la

(3) "En la tradición aristotélica el concepto viejo-europeo de la política como una esfera que comprende Estado y sociedad se mantuvo en pie sin soluciones de continuidad hasta bien entrado el siglo XIX". Habermas, El discurso filosófico de la modernidad, Bs.As., Taurus, 1989, p. 58.

(4) Riedel. Hegel fra tradizione e rivoluzione. Roma-Bari, Laterza. 1975, p. 129.

(5) Ibid, pp. 129 y 130.

(6) Riedel, El concepto de "sociedad civil" en Hegel y su origen histórico; en Autores varios, Estudios sobre la "Filosofia del derecho" de Hegel, Edición preparada e introducida por Gabriel Amengual Coll, Madrid, Centro de Estudios Constitucionales, 1989, p. 201. 
hallamos, al menos conceptualmente, inclusive en Hobbes, a través de su concepción de la unio civilis, que culmina el status naturalis con el sometimiento de los ciudadanos al Estado.(7) También John Locke participa de la mentada confusión, al titular el capítulo VII de su obra Dos tratados sobre el gobierno (1689) como "De la Sociedad Política o Civil" (O) Political or ('ivil Society) (8). Ya dentro de las tradición alemana, C. Wolff definió a la ciencia política como: "Quella parte della filosofia. nella quale l'uomo é considerato come vivente nello Stato (in Republica) ossia Stato civile si chiama Politica. La Politica é quindi la scienza del dirigere le libere azione nella societá civile ossia Stato" (9). Kant, en la Metafisica de las costumbres (1797), Primera Parte. $\$ 45$, interpreta al Estado como civitas (10), y en el $\$ 46$ equipara a la sociedad civil-estatal con la sociedad civil (11). El término utilizado por Kant ("Staatsbürguer"), resultó ser un neologismo para sus contemporáneos, quienes al comienzo lo rechazaron.

- Notamos cómo el sentido originario de la polis clásica ha desaparecido radicalmente del mundo occidental. Lo que en el análisis de la vida en Roma y del tipo de libertad vigente, proceso iniciado a partir de la helenizaciòn del mundo griego, veníamos señalando como un cambio de signo radical que se venía operando en la sociedad, ahora, en los epígonos de la modernidad, puede observarse en la plenitud de su manifestación: la identificación moderna entre "sociedad civil" y "Esta-

(7) Ibid., p. 202.

(8) Loc.cit.

(9) Chr. Wolff, Philosophia rationalis sive Logica (1740), Discursus preliminares, cit., cap. III, $\S 65$; citado por Riedel, Hegel fra tradizione e rivoluzione, p. 131.

(10) Riedel, El concepto de "sociedad civil" en Hegel, p. 202.

(11) Loc.cit. 
do" coloca el acento en el primero de estos términos, olvidár dose del contenido presente en el último, o en el mejor de los ca. sos relegándolo a un plano secundario. En definitiva, esta identificación no traía aparejada otra cosa que la pérdida de la libertad positiva, en contraposición a lo que había acontecido en épocas de la polis griega.

\section{Hegel: ruptura con la identificación moderna Objetivo: llamar a cada cosa por su nombre}

El pensamiento político de la antigüedad clásica y el de la modernidad se unen en un punto, en relación con los derechos de la persona. En rigor de verdad, deberíamos decir, mejor, que en este punto crucial es donde se separan radicalmente. La asociación viene dada por el hecho de que ambas épocas negaron la existencia de dos realidades relacionadas con los derechos de la persona y el modo de libertad ejercida a través de estos derechos. La uniformidad del lenguaje acerca de la identificación entre sociedad civil y Estado que perduró hasta fines de la modernidad, exceptuando la filosofía de Hegel, encubrió una sustancial transformación: la libertad positiva (y única existente en el mundo griego) trocóse en libertad negativa con los modernos (12). Ambigüedad del lenguaje que "encubría la trama de las relaciones sociales y económicas sobre las que se apoyaba el Estado antiguo, la institución de la esclavitud o las relaciones de señorio y servidumbre..." (13). Tradicionalmente estos términos tuvieron el significado de unión entre los

(12) Riedel, Materialen zu Hegels Rechtsphilosophie, p. 255; citado por De Zan, La interpretación hegeliana de la Sociedad Civil en Europa y en América. Publicado en Cuadernos Salmantinos de Filosofia-VIII, Salamanca, 1981 , p. 46.

(13) Loc.cit. 
hombres para realizar un fin común, objetivo y universal. Para la modernidad, en cambio, sociedad civil consiste en la delimitación y garantía de los derechos individuales y de la propiedad privada (14). Atento a esta transformación operada en la cultura occidental, Hegel señalará su equívoco poniendo en evidencia la ambigüedad del lenguaje y la magnitud del significado de este doble encubrimiento. Su esfuerzo habrá de concretarse en una clarificación de los términos utilizados para estas dos realidades distintas. a la vez que se ocupará de conciliarlas en su diferencia (15). Hegel establece una separación de esferas: Estado y sociedad civil, término éste que ya no será más sinónimo de "político", sino que recibe un contenido social, antes ausente. Desde Locke, y luego durante toda la modernidad, en la identificación entre sociedad civil y Estado lo que se encubre no es ya la vida privada de la persona, sino la falta de sentido ético de lo político. El Estado liberal burgués no es más que una institución que custodia las libertades individuales. El objetivo de Hegel, al separar las dos esferas, es recuperar el sentido de lo político, que el Estado no sea simplemente un medio al servicio de intereses privados -y egoístas- de los individuos, tal como sucedía con las teorías individualistas modernas. La concepción hegeliana de la sociedad y de la política se constituye así en la síntesis del pensamiento occidental: heredero y crítico de la tradición clásica griega, no pudo menos que integrar un aspecto básicamente moderno, la conciencia subjetiva y el ámbito de lo privado, que desde la crisis de Francfort, y atento a las transformaciones del mundo en que vivía, ya no pudo dejar de reconocer y valorar.

"En el sistema hegeliano se recoge la historia del mundo occidental, desde Grecia al cristianismo, al Derecho romano, a la acentuación de la individualidad que ha 
sido afirmada por los tiempos modernos. En éstos, la reforma protestante, la concepción iusnaturalista, la ilustración, la misma industriosidad burguesa, en fin, la filosofía kantiana y la Revolución Francesa, han perfeccionado el descubrimiento cristiano del valor infinito del singular, lo ha despertado con todas sus potencialidades. Grecia no conocía este valor, porque la libertad del singular se identificaba con la libertad de la polis, no se diferenciaba de ella..." (16).

El gran cambio operado por Hegel en su teoría sociopolítica es el haber concedido un ámbito propio a la sociedad civil (17). Al estructurar la sociedad civil en tres momentos dialécticos, Hegel salvaguarda el sistema de intereses privados, tanto en lo que toca a los derechos inherentes a la persona, como en los que intervienen en la actividad económica, como así también aquellos que tienen que ver con su protección y resguardo, garantías posibles, éstas, gracias a la existencia de instituciones diseñadas para tales fines. Se establece, de este modo, un sistema de autocontrol mutuo capaz de asegurar la realización conjunta de las libertades individuales.

Hegel, al tematizar la relación entre la sociedad civil y el Estado, respondiendo de tal manera al modo en que se relacionan los intereses particulares con los universales, está objetando la gran confusión en que ambas esferas permanecieron desde la antigüedad hasta su tiempo.

\section{¿Qué integra Hegel en su concepto de "sociedad civil"?}

A partir del mundo romano, y el surgimiento del derecho privado, del cristianismo y de la Reforma luterana, Hegel

(16) Marini Giuliano, Estructuras y significados de la sociedad civil hegeliana, en Estudios sobre la "Filosofia del Derecho" de Hegel, p. 228.

(17) De Zan, La interpretación hegeliana de la Sociedad Civil en Europa y en América, p. 47 y 48. 
recupera el principio de la libertad subjetiva. Su concepto de "sociedad civil" incluye los derechos naturales, a saber, de propiedad, trabajo, libertad de expresión, circulación. etc. Al hablar de "sociedad civil burguesa" queda establecida su relación con los filósofos sociales de la modernidad: Hobbes, Locke y Rousseau. Del primero toma su concepción del Estado de naturaleza y Estado político, incluida la noción de "violencia". De Locke, las nociones de trabajo y propiedad. De Rousseau su concepto de "voluntad general". Su concepto de "sociedad civil" proviene de la obra de Adam Ferguson (18), An Essay on the History of (ivil Society (1767). De Adam Smith toma su teoría de la riqueza de las naciones, junto a la idea de que existen reglas en el proceso de desarrollo del Mercado y su teoría sobre "la mano invisible" (astucia de la razón). Del liberalismo francés toma la idea del mercado mundial; una sociedad que se desarrolla empieza a exportar sus contradicciones. De Ricardo, y su obra Principios de economía política, la noción de las reglas contradictorias que hacen posible el desarrollo del capitalismo; no hay armonía en las relaciones económicas. De todo esto obtiene, en definitiva, un cruce de caminos entre lo antiguo y lo moderno.

"Desde el punto de vista de Hegel, el cristianismo ha producido un efecto igualmente profundo sobre la cultura europea, especialmente tras haber sido desarrollado por la Reforma y secularizado por la ilustración. Bajo su influencia los hombres han llegado a considerarse a si mismos como agentes morales, no reconociendo autoridad mayor que su propia conciencia o razón. Hegel denomina a la primera tendencia 'particula-

(18) "El término 'sociedad civil' ha sido usado por escritores como Locke, Smith y Ferguson, además de por algunos de sus contemporáneos en Francia, a los que Hegel habia leido. En último término se puede acudir a la aristotélica koinonia politike y la societas civilis de Cicerón". Zbigniew A. Pelczynski, La concepción hegeliana del Estado, en. Estudios sobre la "Filosofia del Derecho" de Hegel, p. 261- 
ridad' y a la segunda 'subjetividad'; ambas constituyen el fenómeno europeo, característico de la vida moderna, del individualismo... Hegel percibió que era la burguesía la que formaba la principal base social del individualismo, y a través de quien la Europa de la Edad Media. tradicional y consciente del sentimiento de comunidad, había sido socavada (19).

\section{Limitaciones de la sociedad civil: de la libertad negativa a una libertad positiva}

Según el punto de vista hegeliano y su modelo de libertad concreta como integración de las libertades positiva y negativa, será necesaria una esfera superior de la vida en que la persona pueda lograr sus aspiraciones y fines que la caracterizan como tal. Nos referimos a la esfera del Estado, verdadero ámbito de la eticidad.

Si la verdadera libertad del hombre se logra solamente en el marco de una comunidad ética regulada por leyes racionales, en una comunidad tal podrán realizarse la esencia y el fin del hombre, que ya en la polis griega existieron, aunque no privados de ciertas limitaciones; éstas habrán de ser a su vez superadas por la conciencia moderna dotada del sentimiento de particularidad, y luego de la asimilación del sentido griego de lo ético se logrará el fortalecimiento de una libertad concreta en que ambos tipos de libertad queden finalmente integrados. El renacer del Ethos comunitario, la Sittlichkeit termina siendo la base y fuente de libertad del hombre moderno (20). El alto nivel de politización de la existencia griega se perdió a partir del

(19) Pelczynski, Zbigniew A.,La concepción hegeliana del Estado, en Estudios sobre la "Filosofia del Derecho" de Hegel, pp. 256-258.

(20) Taylor, Charles, Hegel y la sociedad moderna, México, Fondo de Cultura Económica, 1983, pp. 164 y 165. 
surgimiento de la conciencia individual (21). Las condiciones económico-sociales del mundo moderno han creado una situación tal, que el hombre, debido a este redimensionamiento de su libertad esencial, debe, para desarrollar su vida en plenitud, moverse en dos esferas diferenciadas y complementarias: la de los intereses privados (sociedad civil burguesa) y su complementaria, que contiene el interés universal: el Estado. Hegel intenta, con su diferenciación en estas dos esferas, salvaguardar la vida privada y política del hombre (su libertad negativa y positiva) y dar lugar al burgués y al ciudadano. La sociedad civil será el ámbito en que puede desplegar su libertad negativa; en el Estado podrá lograr su otro fin esencial, ligado a una libertad positiva: desarrollarse como ciudadano y participar, así, de las decisiones políticas que le competen (22).

\section{Racionalidad de la subordinación de la sociedad civil al Estado}

En la sociedad civil, el burgués, el individuo, es plenamente libre, capaz de poseer y negociar propiedades según le plazca, entrar en el libre juego de la competencia, pertenecer a una familia y/o grupo social determinado, educarse, establecer contratos de cualquier índole, etc. Pero, a pesar de la apariencia de abundancia de libertad de la que aquí goza, su libertad ha de

(21) "...Hegel reconoce 'el derecho de la libertad subjetiva que constituye el punto de viraje y el núcleo de la diferencia entre la antigüedad y la época moderna" (\$124 A). Se trata del derecho del individuo a su autorrealización y' al libre despliegue de su particularidad (o de su plan de vida), el cual tendrá su lugar y el reconocimiento de su derecho en las instituciones de la eticidad, especialmente en el ámbito de la sociedad civil". Julio De Zan, Moralidad y eticidad, o Kant y Hegel, en Cuadernos de ética, $\mathrm{N}^{\circ} 7$ (junio de 1989), p. 13.

(22) Aranda, Fernando, La postura socio-política de Hegel, Tesis de Licenciatura no publicada (Santa Fe, UCSF, 1994), pp. 54 y 55. 
resultar superada y profundizada en el sentimiento de pertenencia a su comunidad y al Estado. Aquí el burgués participa de la riqueza universal, lo cual sólo ha de ser posible a partir de una toma de conciencia comunitaria.

A la sociedad civil se le concede en la filosofía de Hegel una relativa independencia; en la medida en que posee mecanismos de coordinación entre el intercambio de intereses particulares posee autosuficiencia, pero si éstos entraran en pugna, entonces se tornaría necesaria la existencia de otra esfera superior que la regule: el Estado. El bienestar y el derecho del individuo poseen una existencia precaria, su universalidad se queda en el nivel de la apariencia, por eso Hegel denomina a este sistema de intereses privados "el Estado externo o Estado de la necesidad y del entendimiento" (23).

Si bien el Estado permanece por encima de los intereses de la sociedad civil, ésta goza de cierta independencia, capaz de permitirle a sus miembros el ejercicio de su libertad negativa. De acuerdo a lo que veníamos expresando anteriormente, al explayarnos sobre la ruptura hegeliana con la identificación moderna entre sociedad civil y Estado, Riedel afirma la mutua independencia de ambas esferas, en virtud de la cual es posible que "entablen su verdadera relación", hecho que separa la concepción hegeliana del derecho natural, pues queda claro que para el filósofo suavo "el Estado no es Estado si ya coincide con la sociedad civil, ni ésta tampoco es 'sociedad', si es 'política', o sea, Estado" (24).

(23) Hegel, Filosofia del Derecho (Edición revisada por Laura Mues de Schrek y Eduardo Ceballos Uceta, Segunda Edición, México, Universidad Nacional Autónoma de México), § 183.

(24) Riedel, El concepto de la "sociedad civil" en Hegel y el problema de su origen histórico, p. 200. 
Hegel, por intermedio de su complementación de esferas. sociedad civil y Estado, salvaguarda la universalidad del hombre sin perder de vista el desarrollo de su individualidad; la libertad empírica se transforma en libertad real. Si el Estado es tomando como sociedad civil, la libertad del hombre será falsa; sólo en la esfera superior del Estado el hombre es verdaderamente libre. La sociedad civil es el Estado del liberalismo económico; restringir la libertad humana a una existencia exclusiva en esta esfera es destituirla de su sentido primigenio. Tal subordinación no implica que el Estado deba lesionar los derechos que posee la sociedad civil (25). Hegel se preocupó por asignarle a este mundo de la sociedad civil, sus valores específicos, libertad económica, intelectual, religiosa y leyes igualitarias. Pero del mismo modo que es destacable esto en Hegel, también queda claro que aquel mundo "de lo privado" debía ser trascendido dialécticamente en una esfera superior, el Estado. Así, el ciudadano-bourgeois se troca en el ciudadano-citoyen.

\section{La sociedad civil después de Hegel}

A partir de Hegel se observa un declinar semántico en el concepto de "sociedad civil". Nos referimos a una doble y ambivalente transformación (e interpretación) del significado de la "sociedad civil". Marx interpreta a la sociedad civil hegeliana a la manera de un símil con el "estado de naturaleza" de Hobbes, semejanza que en cierto modo ya se percibía en la filosofía hegeliana (26). La sociedad civil pierde definitivamente el resto de su significación positiva y es percibida como el lugar del egoísmo de los individuos, que con tal de acumular sus riquezas

(25) Hippolite, Jean, Introducción a la Filosofia de la historia de Hegel, Montevideo, Edit. Caldén, 1970, pp. 118-124; Aranda, Op.cit.. p. 164.

(26) De Zan, Op.cit., p. 79. Marini, Op.cit., p. 243. 
materiales no dudan en explotar a sus semejantes olvidándose de todo principio moral que intente limitar su libre accionar. Marx propone la creación de una sociedad igualitaria, fundada en la eliminación de la propiedad privada de los medios de producción, eliminando la diferencia entre sociedad civil y estado. Para Marx, la sociedad civil "aparecerá siempre menos civil y siempre más burguesa, pero en todo caso sociedad de individuos dominados por el egoísmo, y digna de ser sustituida por la 'sociedad humana' o por la 'humanidad devenida social". (27). En Hegel, la expresión alemana "Bürgerliche Gesselschaft" tiene un doble significado, a saber, "civil" y "burguesa". La eliminación de la diferencia entre Estado y sociedad civil, hecha efectiva por los regímenes socialistas "significó en la práctica la supresión de la autonomía de la iniciativa privada de los individuos en la generación de la cultura y de la riqueza" (28), lo cual no dio el resultado esperado, ni en cuanto al crecimiento individual, ni social, ni cultural ni económico, sino al contrario (29).

Por la otra parte, el liberalismo ha contribuido a que se produzca un proceso de signo contrario, reduciendo el conjunto de valores que Hegel le había asignado a su concepto de "sociedad civil" a lo puramente económico: los valores de la sociedad civil apuntan a resolver pura y exclusivamente las necesidades humanas, materialmente hablando. Muchos pensadores liberales de hoy intentan apropiarse de la concepción hegeliana sobre la "sociedad civil", desnaturalizándola, vaciándola de sus contenidos éticos y culturales.

De tal índole ha sido la reducción que han hecho del concepto de "sociedad civil" tanto el marxismo como el liberalismo. Pasemos, a continuación, al análisis de lo que el liberalis-

(27) De Zan, Op.cit., p. 80.

(28) De Zan, Op.cit., p. 81.

(29) Loc.cit. 
mo entiende como "libertad", para ver si luego podemos acercarnos a precisar qué aspectos del liberalismo podrían corregirse por medio de la sociología y la política hegelianas a partir de su división y la significación asignada a las dos esferas de la "sociedad civil" y el "Estado", y el tipo de coordinación entre ambas.

\section{Concepto liberal de "libertad"}

Para el liberalismo la palabra "libertad" ha estado desde siempre en un pedestal, como el valor central de lo político (30). Ahora bien, se nos ocurre una pregunta: ¿qué clase de libertad es la que propugna el liberalismo, para que desde ésta o, mejor dicho, desde su propia posición política, sea juzgada como no favorable a la libertad, en el mejor de los casos, cuando no autoritaria, toda posición que no coincida con la definición?

La ideología liberal del Siglo XIX, a partir de su filiación con la Revolución Francesa, se opuso francamente a los absolutistas y partidarios de la Restauración. Los liberales tuvieron como principal estandarte el reclamo de los derechos individuales, de la libertad de prensa y de expresión, de reunión, de asociación, etc. Esto habría de ser conseguido limitando la autoridad del soberano y del Estado, para lo cual era imprescindible una activa participación de la burguesía en la administración y legislación del Estado (31). El liberalismo de los epígonos de la modernidad fue una ideología típica de la burguesía (32). Esta clase social, que desde el resurgimiento del comercio venía manifestando un sostenido ascenso, concebía al

(30) De Zan, Op.cit., p. 55.

(31) Nahum, Benjamín, El pensamiento politico y social en el siglo XIX, Bs.As., Edit. Kapelusz, 1972, p. 11.

(32) Ibid., p. 12. 
Estado como juez y gendarme de la sociedad. El Estado estaba para salvaguardar las libertades individuales; no tenía en sí mismo una razón de ser, es decir que en última instancia asumía un valor negativo, sólo debía poner límites. Uno de los fenómenos concomitantes del liberalismo y que más peso tuvo en la toma de decisiones y de juicios de valor a partir de su totalidad ideológica, es el liberalismo económico.

Sus principales antecedentes están en los fisiócratas franceses, quienes sostenían que lo económico era un fenómeno natural y por ende, las leyes naturales dejaban a la economía librada a su propia libertad, sin intervención alguna del Estado. Permitir la mayor iniciativa individual posible en el campo económico, sin trabas de ningún tipo, era su predicamento, que se resumía en la frase "laissez faire, laissez passer". Casi contemporánea a los fisiócratas franceses surgió en el panorama económico-político de la época la escuela clásica de economía, con Adam Smith, Malthus y Ricardo, figuras verdaderamente paradigmáticas del liberalismo económico. Tanto los fisiócratas como los economistas clásicos pusieron el acento en la libertad individual de la actividad económica, -si bien hoy día juzgaríamos como demasiado optimista o aséptica en exceso su teoría "đe una sociedad que se autorregula- en coincidencia con el dogma del liberalismo político sostenido por la burguesía. El liberalismo político y el liberalismo económico, especialmente en Inglaterra, cuna de la Revolución Industrial, fueron dos caras de una misma moneda.

Según el liberalismo el hombre nace libre y la libertad es un don de la naturaleza. La sociedad y el Estado restringen aquella originaria libertad natural ilimitada. De acuerdo con todo esto un Estado será liberal en la medida en que utilice su "poder" para limitar, a su vez, las restricciones al mínimo indispensable; con ello tenemos, entonces, el llamado "Estado míni- 
mo". El liberalismo intenta salvaguardar el ámbito de la libertad negativa; los derechos del individuo son resguardados, de esta manera, frente al Estado que se le opone. Hay aquí una clara manifestación de desconfianza fundamental ante cualquier poder político (33). Esta manera de entender al Estado no ha hecho otra cosa que desnaturalizarlo, al intentar reservarle un papel de simple guardián de lo que hacen sus miembros. El Estado está ahí para cuidar el libre desenvolvimiento de las particularidades en la sociedad civil, notemos lo que al respecto escribe un fiel seguidor de la tradición liberal, en la línea de Alexis de Tocqueville y Raymond Aron:

"El fundamento del liberalismo, repitámoslo, es la distinción entre la sociedad civil y el Estado: éste es el representante y el instrumento de la_sociedad civil. La sociedad civil tiende a bastarse a sí misma: en su seno, los miembros de la sociedad no están gobernados por el poder político ni por otros miembros, sino que cada uno es la fuente de sus acciones... En_cuanto al Estado que representa y que sirve al instinto de conservación de los individuos, promulga y hace aplicar las leyes que garantizan a cada individuo la seguridad y la libre busca de la felicidad, de conformidad con la idea que cada cual se hace de ella. Esos son los principios..." (los subrayados son nues tros) (34).

\section{Hegel y el liberalismo clásico}

Comparado con los principales representantes modernos del pensamiento liberal, en muchos puntos, y, casi diríamos sin temor a equivocarnos, en aquellos que competen a los derechos humanos, Hegel aparece como menos autoritario y más respetuoso de la libertad que aquéllos. A saber: Locke otorga un

(33) De Zan, Libertad, poder y discurso, pp. 62-64.

(34) Manent, Pierre, Historia del pensamiento liberal, Buenos Aires, Emecé, 1990, p. 153. 
excesivo poder (absoluto) a los propietarios sobre sus esclavos, esto es así puesto que Locke sostiene que las relaciones económicas están exentas de cualquier tipo de control estatal; a la hora de dirimir entre dos libertades aparentemente contradictorias, Locke se decanta del lado autoritario (35). Hegel, que además de afirmar que el valor del hombre radica en el propio hecho de ser hombre y no por estar definido por categoría alguna (36), rechazó abiertamente la sociedad esclavista antigua, criticando precisamente en ella el ocultamiento de tales hechos.

Hegel se opone -denunciándolo- a Kant, quien es tradicionalmente visto como liberal, en relación a los derechos de los padres sobre los hijos, derechos que Kant entendía como que los niños eran parte de la propiedad de sus padres, quedando del lado de la antigua tradición romana, "en que los niños eras asimilados como esclavos del padre de familia" (37). Hegel reclama la instrucción de los menores y su exención de trabajos insalubres; la autoridad de los padres queda limitada ante tales inconvenientes que lesionarían los derechos de sus hijos. También Höffe, con respecto a esto afirma el autoritarismo de Kant, agregando que defiende al más fuerte (38) y que precisamente, en cuanto al tema de los derechos de los niños, los considera como "ciudadanos de segunda clase", en relación con el resto de los ciudadanos. Hegel critica también a Kant en cuanto a su intención de construir el matrimonio "como un contrato de personas

(35) Losurdo, Doménico, Hegel et le libéraux. Liberté Egalité - Etat, París, Presses Universitaires de France, 1992, p. 111.

(36) Hegel, Filosofia del derecho, § 209.

(37) Ibid., § 110.

(38) Höffe, Iimmanuel Kant. Barcelona, Edittorial Herder, 1986, pp. 204 y 214. 
autónomas", lo cual Hegel valora como una "vergüenza" (39).

Schelling fue llamado por el gobierno de Berlín, una vez muerto Hegel, para contrarrestar la influencia de su pensamiento; sabido es el hecho de que Schelling también preconizó en su obra política un Estado limitado, al modo de guardián del espacio privado de los individuos (40). Constant, e incluso Gentz (ideólogo de la Restauración), rechazaron expresa y abiertamente cualquier forma de intervención estatal en la sociedad. Pues bien, ¿qué diremos entonces cuando Hegel plantea tales intervenciones a fin de que los padres eduquen a sus hijos o que empresarios inescrupulosos no obliguen a menores a trabajar en las minas? ¿Juzgaremos a Hegel como autoritario por esto, y a los demás como liberales. respetuosos de las libertades? Ante tamaños abusos sociales no es posible negar al Estado su obligación de proteger los derechos de los menores (41).

Hegel "no compartía la ilusión de los economistas utilitarios, en el sentido de que el "laissez-faire" es parte de una orden inmutable de la naturaleza, sino que sugería más bien la idea de Marx de que se trata de una etapa particular del desarrollo social" (42). Su crítica al jacobinismo francés era sólida. "en nombre de la libertad destruía con frecuencia sin miramientos formas de organización social que tenian un propósito útil y de una manera u otra tuvieron que se reimplantadas por el interés del propio liberalismo" (43). Hegel obliga a una reformulación del liberalismo, a partir de su teoría ética de

(39) Ilting, Karl-Heinz, La estructura de la "Filosofia del derecho" de Hegel, en Estudios sobre la "Filosofia del Derecho" de Hegel, p. 73.

(40) Losurdo, Op.cit., p. 113.

(41) Ibid., p. 108. Fernando Aranda, Op.cit., pp. 156-161.

(42) Sabine, George, Historia de la teoria politica, México, F.C.E., 1945, p. 482.

(43) Loc.cit. 
la libertad y su relación con la autoridad, todo lo cual coincidía con su crítica al individualismo (44). "El individualismo falsea la naturaleza de las instituciones sociales, porque las considera como accidentales y diferentes al desarrollo moral y espiritual de la personalidad, como simples ayudas utilitarias inventadas para satisfacer los deseos irracionales de los hombres" (45). A partir de Hegel la política resultó enriquecida; el legalismo y el individualismo "fueron complementados por el estudio histórico de las instituciones y por una comprensión más concreta de los factores sociales y económicos en el gobierno y la psicología humana" (46). El hegelianismo sirvió a la revisión del liberalismo inglés por parte de los idealistas de Oxford, "la influencia importante fue la búsqueda de Hegel y toda la sólida crítica del individualismo, a la que el progreso de la industrialización prestaba una urgencia que Hegel nunca sintió" (47).

\section{Conclusión: Hegel y el neo-liberalismo}

En estos tiempos "liberales" que corren, el pensamiento de Hegel también tiene algo que decir, sin riesgos de caer en anacronismos. Sobre todo si tomamos el pensamiento político de Hegel, no para hacer de él un pensador liberal o anti-liberal, ni el paradigma de una teoría política, etc., sino, por el contrario, tratando de hallar en éste ciertos aspectos de su teoría que sirvan como correctivos de situaciones problemáticas en el mundo político actual.

El liberalismo de hoy, bien sabemos, no conforma un sólido bloque de pensamiento en el mundo. Están las posturas más clásicas, conservadores, partidarias del "Estado mínimo",
(44) Ibid., p. 477.
(45) Ibid., p. 478.
(46) Ibid., p. 486.
(47) Ibid., p. 487. 
de la mínima interferencia posible por parte del gobierno hacia los particulares, y aquellas otras formas más moderadas, donde las libertades individuales sí son debidamente respetadas, pero no a la manera del Estado mínimo, sino en una búsqueda constante de que este desarrollo de las libertades sea lo más igualitario posible, otorgando medios por los cuales lo valores que hace a la vida humana queden salvaguardados ante el embate de cualquier agente siniestro que pretenda coartarlos. Podríamos mencionar, hoy, como representantes de ambas tendencias, al modelo capitalista anglo-americano, por un lado, y a los gobiernos social-demócratas de los países escandinavos en el otro extremo: tomando el caso de lo que ocurre hoy en España, la comparación se transfiere, aunque guardando las distancias, a los modelos representados por el "Partido Popular" y el PSOE, respectivamente. Ahora bien, ¿qué papel juega el Estado hegeliano en todo esto? Si bien, como ya dijimos antes, no es el modelo a seguir hoy, y aquí el motivo posmoderno del fin de los grandes relatos puede ser una de las razones. creemos que aquella búsqueda hegeliana de una real complementación entre las libertades negativa y positiva le otorgarían a una teoría política un carácter moral antes que utilitario. Un Estado que se preocupe de proveer los medios adecuados para que sus ciudadanos puedan convivir dignamente, será un Estado ético en que las leyes racionales tendrán plena vigencia. En definitiva, entre la libertad negativa y positiva cabe la comparación hecha por Erich Fromm, respecto a las dos modalidades de la existencia: "Para lograr una sociedad basada en el modo de ser. (libertad positiva), todos sus miembros deben participar activamente en su funcionamiento económico y como ciudadanos. Por ello. nuestra liberación del modo de existencia de tener (libertad negativa), sólo es posible mediante la plena realización 
86 - Fernando Aranda Fraga

de una democracias que permita la participación en la política y en la industria" (48).

(48) Fromm, Erich, ¿Tener o ser?, México, F.C.E., 1978, p. 170. 